\title{
The Educational Interrelation of Narrative Creativity and Written Expression Dimensions as an Innovative and Didactic Process in Learning a Foreign Language
}

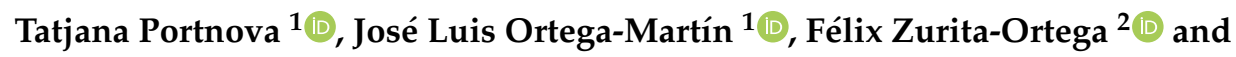 \\ Gabriel González-Valero ${ }^{2, * 1 D}$ \\ 1 Department of Didactics of Language and Literature, University of Granada, 18071 Granada, Spain; \\ tportnova@ugr.es (T.P.); ortegam@ugr.es (J.L.O.-M.) \\ 2 Department of Didactics of Musical, Artistic and Corporal Expression, University of Granada, \\ 18071 Granada, Spain; felixzo@ugr.es \\ * Correspondence: ggvalero@ugr.es; Tel.: +34-958248949
}

Received: 15 August 2020; Accepted: 29 August 2020; Published: 4 September 2020

\begin{abstract}
The aim of the present study was to analyze the impact of narrative creativity on the subject of written foreign languages in secondary school students. A quasi-experimental longitudinal study was conducted with 117 students of 14-15 years of age in two secondary schools in Andalusia (Spain) with experimental and control groups. The tools used were a writing expression analysis tool designed by the authors and the Creative Imagination for Youngsters Test (Prueba de Imaginación Creativa para Jóvenes, PIC-J). The results showed that the participants of the experimental groups improved in terms of the originality and usage of variables of imaginary elements. We also found gender differences-in favor of female students-in the experimental groups in terms of foreign language improvement during the study. Finally, there was a slight interrelation of students with higher narrative creativity showing greater improvements in their written expression skills.
\end{abstract}

Keywords: narrative creativity; foreign language learning; written expression; secondary education

\section{Introduction}

A language is always a part of a certain culture. Learning a second language allows one to become immersed in this culture and, through this process, to understand its representatives. In this way, language learning forms part of a process of fostering cultural sustainability in which the individual learns to respect the values of another culture. The aim of this work is to demonstrate the role of creativity in this process. Recent studies have associated creativity with several personal and cognitive benefits: divergent thinking [1,2], the capacity for problem solving [3], tolerance to ambiguity, varieties of interests or self-discipline [4]. In this manner, creativity studies show that creativity develops several personal values that make people more flexible in their behavior. Therefore, creativity in language classes can be treated as a tool to enhance cultural sustainability.

In the academic field, studies that demonstrate the relationships between creativity and academic achievement have been conducted; for example, in language disciplines [5] and in the area of creativity and intelligence [6-8]. However, Getzels and Jackson [9], Torrance [10,11] and Michalko [12] highlight that creative capacities are different from intelligence. Srinivasan [13] suggests that only some forms of intelligence (for example, fluent intelligence) can be a determinant factor for creativity. This demonstrates the polarity concerning the relationship of creativity with academic achievement; however, the paucity of studies that have been conducted in this field show the necessity for continued research on the topic. 
At the same time, in recent years, a number of studies have been conducted that underline the importance of creativity in education. Following the analysis of Smith and Smith [14], after Guilford, the researchers that have contributed most to the role of creativity in education are Amabile [15], Runco [16], Renzulli [17] and Sternberg [18]. Craft [19] observes that there has been a series of studies highlighting the importance of creativity in education since the 1950s. A large number of programs have been developed to foster creativity. Nevertheless, the transfer of these programs is minimal, due to a lack of uniformity, systematic incorporation and monitoring. The importance of creativity is recognized, but in the context of a school, it is a frequent occurrence that no real approach to foster students' creativity can be found. This fact is observed by Beghetto [20], who insists that creativity has a limited role in the classroom context, despite preceding key psychologists naming it as an objective of education [21,22]. There are several reasons to claim that creativity should be present in school classrooms. According to Cuevas-Romero [23], we have to change the current educational system towards encouraging creative processes that foster creativity. Children who develop creative capacities are more integrated into society and more flexible when developing all types of habits. Nevertheless, education is separated from creativity, and the importance of creativity in classrooms is ignored [24,25]. Constantinides [26] highlights the importance of courses that are specifically designed to foster creativity in teachers, and also names creativity as an important skill in the process of language teaching. A number of studies have demonstrated the connection between learning and creativity [27-30]; however, there is still lack of agreement about whether creativity is present in schools. As Hennessey [31] stresses, studies are still needed that aim to establish a clear relation between creativity and learning.

Furthermore, in the academic field of language education, we can also find increased interest towards creativity. The Common European Framework of Reference for Languages [32] clearly distinguishes two approaches to teaching foreign language writing skills: "creative writing" and "written reports and essays". It is important to emphasize that the Companion Volume with New Descriptors [33] remarkably expands the descriptors for creative writing for all language levels (A1-C2), demanding that attention be paid to the value of creativity in foreign language teaching. The modern methodology of foreign language teaching uses communicative methods and task-based learning, which implies that students have to use their imagination, and this leads to the need for more attention to be paid to creativity [34]. In the same way, Sternberg [35] highlights that creativity is inseparable from teaching foreign languages. When speaking about language teaching and learning, it is difficult not to take creativity into account. Chomsky [36,37] states that language itself is creative, as the tendency is not to repeat learned phrases, but to combine the learned expressions in a creative way. Thus, we consider it important to pay more attention to creativity in foreign language classrooms, as there seems to be general agreement regarding its importance, but a real lack of its practice.

The definition of creativity followed in the present study is based on the criteria of the authors for the creativity test applied in this study [38]: "Creativity is the interaction between aptitude, process and the environment by which an individual or group produces a perceptible product that is both novel and useful as defined within a social context" [28] (p. 90). We agree that this definition treats creativity as a process; this context is essential when discussing the learning process in education.

In the present study, we applied a restricted area of creativity, i.e., narrative creativity. In the area of creativity, narrative creativity and figural creativity can be distinguished [38]. Narrative creativity is a measure of divergent thinking applied to the solution of problems of verbal content, where the figural applies to the non-verbal contexts. As we are working with language learning in this study (i.e., a purely verbal context), it was decided to approach narrative creativity instead of general creativity.

\section{Previous Studies}

Ghonsooly [39] emphasizes that although multiple studies connect bilingualism, creativity and its impact on everyday life, there continues to be a shortage of studies that explore foreign language learning from the perspective of creativity in the context of the classroom. Nevertheless, a large number 
of studies have been conducted regarding creativity in bilingual children. Ricciardelli [40] analyzes 24 different studies that examine creativity and bilingualism, concluding that 20 of them demonstrate that bilingual children have higher levels of creativity compared to monolingual children. One study does not find any difference between the two groups and three show the opposite finding. Ricciardelli highlights that the four studies that do not find this connection do not take into account the level of the language. The statistics and arguments obtained by Ricciardelli make a strong contribution to the approach of the relationship between creativity and several factors of language.

Landry [41] notes the impact of foreign language learning on the divergent thinking of students as well as their creativity. This study also demonstrates that improvement can only be detected in students with higher levels of language proficiency. As for the cognitive results, certain development is needed. This same idea later reemerges with Cummins [42], who insists that bilingual children must reach a high language level to produce changes in cognitive capacities.

Van Dijk, Kroesbergen and Blom [43] also investigate the association between bilingualism and creativity, presenting a wide review of the literature. They conclude that varying researchers found overwhelming evidence that bilinguals outperform monolinguals at creative tasks.

Other studies investigate influence from the opposite direction, i.e., how creativity impacts bilingualism [44-47]. These studies underline the logical bidirectional relationship between bilingualism and creativity, which we highlight when defining creativity. Creativity is related to several factors, and it is impossible to analyze it as a separate phenomenon. Therefore, all the findings that create a relationship between bilingualism and divergent thinking, fluency and non-verbal creativity should always be viewed through the prism of all the possible interactions that may take place.

Studies about bilingualism define it as the dominance of more than one language and fluent expression in both. Here, the logical relationship between language learning and creativity arises: if, in bilingual children (even if we take bilingualism into consideration in a narrow sense, i.e., those who acquired both or more languages since childhood), we find a correlation between creativity and the number of languages spoken, it would be logical to hypothesize about the creativity levels in anyone learning a language. Nevertheless, the studies in the field of creativity and its impact on language learning are scarce and the results are lacking uniformity. Moreover, in their study, Ottó [48] detects the positive impact of creativity on foreign language students based on originality, sensibility towards problem-solving, fluency in creating ideas and fluency of associations. The results demonstrate that students with higher creativity levels have better foreign language proficiency. Furthermore, Pishghadam and Javdan-Mehr [34] detect a strong association between creativity and the language level in a study with Iranian university students, comparing creativity indicators with the production of written texts in a foreign language. They detect the strong connection between narrative flexibility and the proficiency level of the foreign language. These findings point out the important role of creativity in the foreign language learning process, both at linguistic and extralinguistic levels.

In their first study, Albert and Kormos [49] obtain similar results about the positive impact of creativity on language learning. In a study with Hungarian students in secondary school, they demonstrate that students with higher levels of creativity have better oral production in a foreign language. However, in a later study, Albert [50] analyzes the relationship between creativity and general proficiency of a foreign language. The results show the negative correlation between fluency and flexibility and the capacity for phonetic coding. The author suggests that the possible reason could be that the mechanical tasks in the study do not imply the use of creativity. He also highlights the shortcomings of a transversal and non-longitudinal study, as well as the limited number of participants, which is $\mathrm{N}=41$. We can agree that with mechanical parts of language learning such as phonetic abilities, it may be logical not to find creative interaction, as such processes imply pure mechanical learning techniques.

Ghonsooly [39] carries out a more complete study in monolingual children and English as a foreign language for students (16-18 years, $N=120$ ), applying the creativity test questionnaire to detect the socioeconomic and cultural level, as well as their intellectual quotient (IQ). This study shows 
the positive correlation between higher foreign language proficiency and divergent thinking, which is explained by the fact that students who learn a new linguistic system also learn cultural and traditional differences. This allows students to practice different points of view that improve cognitive flexibility.

McDonough, Crawford and Mackey [51] find a positive interrelation between creativity and production and coordination among students of English as a foreign language concerning. Nevertheless, they do not find any impact on purely linguistic tasks. This suggests that grammar acquisition may not be related to creative processes.

Sadykova and Shelestova [52] also lead an experimental study based on creative exercises in foreign language learning with 58 students, showing that students increased their creativity, while demonstrating considerable growth in several personality indicators.

Liao, Chen, Chen and Chang [53] analyze the impact of creative pedagogy on English as a foreign language. Their quasi-experimental study $(\mathrm{N}=256)$, with control and experimental groups of longitudinal character (8 weeks), show that creative elements in English teaching improved English learning performance, creativity and motivation to learn. This study appears to be the most upstanding, due to the number of participants (compared with the rest of the studies), but the duration of the project remains to be too short.

As we can observe, the studies held in the field of creativity and language learning are irregular, and the results are contradictory. However, we can note that the majority of the studies show the positive correlation between both factors. This fact leads to the necessity of researching this correlation and also the necessity of applying longitudinal studies about creativity, as transversal studies do not appear to reflect the cognitive changes appearing at the time of exposure to language learning in studies carried out in this field.

The first objective of the present study is to prove that activities based on narrative creativity improve written expression in a foreign language. In relation to this, our hypothesis is that it is expected that the members of the experimental groups present a significant improvement in the dimensions of written expression compared to the control groups.

The second objective is to demonstrate that foreign language students with higher narrative creativity indicators have greater capacity to improve their written language proficiency. Our hypothesis is that students who have improved the most in written expression throughout the intervention project have the highest index of narrative creativity, while those who have not improved have the lowest index of narrative creativity.

\section{Materials and Methods}

\subsection{Participants}

The participants $(\mathrm{N}=149)$ were the secondary school students (i.e., 3rd grade of secondary education) of 2 different schools in the region of Granada, Andalucía, Spain, ages 14-16; nationalities: 111 Spanish, 2 Romanian, 1 American, 1 German, 2 Peruvian. Males $N=50$, females $N=67$. The level of English of the participants varied between A1-B1, corresponding to the level obtained following the school program. One school was situated in an urban area and the other in a rural area. The selection of the compulsory education level was due to the availability of both schools to allot one hour a week to carry out the intervention program based on creative writing workshops and dramatization.

In each school, 2 groups were randomly assigned to be experimental groups $(\mathrm{N}=86)$ and 1 to be a control group $(\mathrm{N}=48)$. Later, those students who did not attend the day of pre-test and/or the day of post-test or did not attend the majority of the classes were excluded from the sample, as it was not possible to analyze their development. The final number of participants was $\mathrm{N}=117$ (86 experimental groups, 31 control groups). By having an odd number of groups in each school, a predominance of experimental groups was chosen over the control groups (at a ratio of 2 to 1 ). 


\subsection{Tools}

For the present study, we developed a tool to analyze written texts of the students of English as a foreign language (Table 1) that analyzes 6 dimensions of written expression and corresponding variables. The designed tool was validated by a committee of experts who reviewed the classification and their comments; recommendations were taken into consideration in the final version of the tool.

Table 1. Writing analysis tool designed by the authors.

\begin{tabular}{|c|c|}
\hline Fluency & $\begin{array}{c}\text { Number of Words } \\
\text { Number of Adjectives (\% of the total of words) } \\
\text { Number of Verbs (\% of the total of words) } \\
\text { Number of Adverbs (\% of the total of words) } \\
\text { Number of Sentences }\end{array}$ \\
\hline Emotions & $\begin{array}{c}\text { Different Emotions } \\
\text { Total Emotions }\end{array}$ \\
\hline Fantasy & $\begin{array}{l}\text { Usage of fantastic elements }(0-2) \\
\text { 0-No fantastic elements present } \\
\text { 1-Appear some fantastic elements } \\
\text { 2-Appear abundant fantastic elements }\end{array}$ \\
\hline Accuracy & $\begin{array}{c}\text { Number of Morphosyntactic Errors } \\
\text { Number of Lexical Errors } \\
\text { Number of Semantic Errors }\end{array}$ \\
\hline Originality & $\begin{array}{l}\text { Original elements, comparing with the rest of the students }(0-2) \\
0 \text {-The text does not present anything original } \\
\text { 1-The test is slightly original } \\
\text { 2-The text is completely original }\end{array}$ \\
\hline Cohesion and coherence of a text & $\begin{array}{c}\text { Number of argument leaps between phrases } \\
\text { Number of Conjuncts (\% of the total of words) } \\
\text { Number of Hedges (\% of the total of words) } \\
\text { Number of Amplifiers (\% of the total of words) } \\
\text { Number of Demonstratives (\% of the total of words) } \\
\text { Number of Subordinated Sentences (\% of the total of sentences) }\end{array}$ \\
\hline
\end{tabular}

This tool was designed based on the criteria for evaluating a written text in a foreign language, and also for analyzing the dimensions related to non-linguistic aspects.

The fluency variables enable analysis of different word categories (i.e., overall number of words, adjectives, verbs and adverbs) and the number of sentences. This can give an overview of the fluency of a student expressed by the level of words and sentences used. The fluency variable was created based on Celaya and Navés [54] and de Haan and van Esch [55].

The cohesion variables quantify the categories used at a syntactic level (e.g., conjuncts, hedges, amplifiers and demonstratives) and the complexity of text syntactics (e.g., subordinated sentences). To make the comparison between students more accurate, all these variables are measured by the percentage of the total number of words or sentences. Additionally, the number of argument leaps between phrases was introduced to control the logical cohesion of a text. The cohesion variables were based on Haan and van Esch [55] and Hinkel [56].

Originality and fantasy variables were created following the measurement system of the "Prueba de Imaginación Creativa para Jóvenes" (PIC-J) [38], used to establish the relationship between creativity and academic results. Following this system of measurement, we can use quantified numbers to make a comparison between different students or to control the same student's progress regarding the originality and fantasy in their writing.

Emotions were introduced into the tool based on the studies of Pennebaker and Seagal [57], Graybeal, Sexton and Pennebaker [58], and the theory of social identity of Tajfel [59,60]. By analyzing the emotions, we can examine the non-linguistic aspects that may reflect the participants' implication 
in their writing. The more emotions are reflected in the text, the more implicated a person can appear to be involved in his or her writing. The different emotions variable measures the total number of different emotions reflected in the text (e.g., happiness, love or fear), and the total emotions variable measures the total number of emotions that are present in the text, even if they are repeated.

The grammar aspects were not relevant for the present study as they were not contemplated in the intervention project based on narrative creativity. Nevertheless, we pay attention to this aspect in the accuracy variable based on Llach [61] to determine the possible relationship of grammar with other elements.

Additionally, the Creative Imagination for Youngsters Test (PIC-J) developed by its authors following the studies of Guilford and Torrance, and incorporating features of research among the Spanish population, PIC-J [38], was used. The test consists of four tasks, with the first three tasks measuring Narrative Creativity (NC).

\subsection{Methodology}

Each experimental group received a course of creative writing in English. The exercises were designed following the main creative writing techniques [62-67] and dramatization. The dramatization was introduced following Hlenschi-Stroie [68], affirming that drama is a tool connected to creative writing that enables students to better understand the activities they are involved in and have a deeper analysis of them. Before the intervention project, the students of the experimental groups had to write a pre-test essay called, "The place where I live". Additionally, the students of the control groups wrote the same essay. After the project took place with the experimental groups, they had to write the same essay. The control groups also wrote both essays, but they did not receive the treatment in between. Both essays were analyzed using the designed tool.

The design of the project is quasi-experimental, inter-cluster with non-equivalent control groups, and the sampling is convenient. The design is $2 \times 2$ ( 2 independent variables with 2 levels each: experimental group/control group, female/male gender). Dependent variables are narrative creativity, originality of essay, usage of fantastic elements, progress (i.e., the increment of the number of lexical-semantic and grammatic elements and the decrease of errors in the second essay). The study was longitudinal with a duration of 4 months. The NC test was taken only once at the end of the project (i.e., the transversal part of the study). The data obtained was analyzed with the SPSS Statistics program (v.24.0, IBM Corp., Chicago, IL, USA).

\section{Results}

\subsection{Originality and Usage of Fantastic Elements}

First, we analyzed the extralinguistic variables: originality and usage of fantastic elements.

The comparison analysis between both essays (pre-test and post-test) was done to compare the differences in written expression for the experimental groups. The students were divided into three groups, following the indicators of narrative creativity (high, medium and low).

The data obtained for the variable originality 1 and originality 2 are available in Table 2 .

After applying Pearson's Chi-Square (statistical contrast $\chi^{2}$ ), it was detected that the variables experimental condition and originality 1 are not associated $(p>0.05)$. Originality 1 and gender have a correlation of $95 \%(p=0.046)$.

In the second essay it can be observed that the variables experimental condition and originality 2 are associated $(p=0.028)$, which indicates that the creative writing project improved the originality of the students in experimental groups. As for the gender, in the second essay it does not relate to Originality $(p>0.05)$, so both genders were receptive to the treatment received.

The data obtained for the variable usage of fantastic elements 1 and usage of fantastic elements 2 are available in Table 3. 
It can be observed that, in the first essay, the variable usage of fantastic elements is not associated with other variables $(p>0.05)$. In the second essay, the results are similar to the originality variable. In the second essay we find a connection between the experimental condition and the usage of fantastic elements $(p=0.042)$. Again, it is shown that the creative writing classes improved the fantastic elements in the written expression of the students.

Table 2. Contingency table with the number of participants in each level for the variables originality and narrative creativity (NC), both essay results.

\begin{tabular}{|c|c|c|c|c|c|c|c|c|c|c|c|c|c|}
\hline \multirow{3}{*}{ Group } & \multirow{3}{*}{ Characteristics } & \multicolumn{12}{|c|}{ Originality } \\
\hline & & \multicolumn{4}{|c|}{ Not Original (0) } & \multicolumn{4}{|c|}{ Slightly Original (1) } & \multicolumn{4}{|c|}{ Completely Original (2) } \\
\hline & & \multicolumn{2}{|c|}{$\mathbf{M}$} & \multicolumn{2}{|c|}{ F } & \multicolumn{2}{|c|}{$\mathbf{M}$} & \multicolumn{2}{|c|}{ F } & \multicolumn{2}{|c|}{$\mathbf{M}$} & \multicolumn{2}{|c|}{ F } \\
\hline \multirow{4}{*}{ Experimental } & NC Essay & $1 \mathrm{st}$ & 2nd & 1 st & 2nd & 1st & 2nd & $1 \mathrm{st}$ & 2nd & $1 \mathrm{st}$ & 2nd & 1 st & 2nd \\
\hline & Low & 16 & 12 & 6 & 1 & 1 & 2 & 1 & 3 & 0 & 3 & 0 & 3 \\
\hline & Medium & 15 & 8 & 18 & 12 & 2 & 4 & 4 & 4 & 0 & 5 & 0 & 6 \\
\hline & High & 5 & 2 & 13 & 5 & 0 & 2 & 4 & 8 & 0 & 1 & 1 & 5 \\
\hline \multirow{3}{*}{ Control } & Low & 6 & 5 & 2 & 3 & 0 & 1 & 1 & 0 & 0 & 0 & 0 & 0 \\
\hline & Medium & 5 & 4 & 10 & 7 & 0 & 1 & 1 & 4 & 0 & 0 & 0 & 0 \\
\hline & High & 0 & 0 & 3 & 3 & 0 & 0 & 2 & 1 & 0 & 0 & 1 & 2 \\
\hline
\end{tabular}

Note: Male (M); Female (F).

Table 3. Contingency table with the number of participants in each level for the variables usage of fantastic elements and narrative creativity (NC), both essay results.

\begin{tabular}{|c|c|c|c|c|c|c|c|c|c|c|c|c|c|}
\hline \multirow{3}{*}{ Group } & \multirow{3}{*}{ Characteristics } & \multicolumn{12}{|c|}{ Usage of Fantastic Elements } \\
\hline & & \multicolumn{4}{|c|}{ None } & \multicolumn{4}{|c|}{ Some } & \multicolumn{4}{|c|}{ Abundant } \\
\hline & & \multicolumn{2}{|c|}{$\mathbf{M}$} & \multicolumn{2}{|c|}{$\mathbf{F}$} & \multicolumn{2}{|c|}{$\mathbf{M}$} & \multicolumn{2}{|c|}{$\mathbf{F}$} & \multicolumn{2}{|c|}{$\mathbf{M}$} & \multicolumn{2}{|c|}{$\mathbf{F}$} \\
\hline \multirow{4}{*}{ Experimental } & Essay & 1st & 2nd & 1 st & 2nd & 1st & 2nd & 1 st & 2nd & 1st & 2nd & $1 \mathrm{st}$ & 2nd \\
\hline & Low & 17 & 11 & 7 & 3 & 0 & 4 & 0 & 1 & 0 & 2 & 0 & 3 \\
\hline & Medium & 16 & 10 & 22 & 15 & 1 & 4 & 0 & 2 & 0 & 3 & 0 & 5 \\
\hline & High & 5 & 3 & 18 & 12 & 0 & 1 & 0 & 2 & 0 & 1 & 0 & 4 \\
\hline \multirow{3}{*}{ Control } & Low & 6 & 6 & 3 & 3 & 0 & 0 & 0 & 0 & 0 & 0 & 0 & 0 \\
\hline & Medium & 5 & 5 & 11 & 9 & 0 & 0 & 0 & 1 & 0 & 0 & 0 & 1 \\
\hline & High & 0 & 0 & 3 & 4 & 0 & 0 & 2 & 1 & 0 & 0 & 1 & 1 \\
\hline
\end{tabular}

Note: Male (M); Female (F).

\subsection{Fluency, Accuracy, Emotions and Cohesion Variables}

\subsubsection{Experimental and Control Groups}

All the grammatical variables were analyzed by creating the average values for essays 1 and 2 of the narrative creativity categories (low, medium or high) and experimental or control conditions. Independent-samples t-tests were applied during the analysis.

The statistically significant variables for the first essay, with differences comparing the control groups with the experimental ones, were found for the percentage of subordinate sentences $(p=0.033)$, lexical errors $(p=0.01)$, number of sentences $(p=0.053)$, percentage of verbs $(p=0.025)$ and percentage of adjectives $(p=0.007)$, with the statistical degree of confidence of $95 \%$, which were results obtained after applying the independent-samples t-tests. This means that the groups had some differences, as we did not apply additional criteria when creating the experimental/control groups, due to the availability of teachers.

In the second essay, the experimental groups do not show statistically significant differences, except for the variable percentage of adjectives $(p=0.007)$. 


\subsubsection{Gender}

Leaving aside the division of experimental/control groups, and comparing the results only by gender, in the first essay we detected that female students show statistically significant results compared to the male students in the following variables: percentage of amplifiers $(p=0.037)$, total emotions $(p=0)$, different emotions $(p=0)$, number of sentences $(p=0.01)$, percentage of adverbs $(p=0.013)$, percentage of verbs $(p=0.045)$. The statistical degree of confidence was $95 \%$, which were results obtained after applying the independent-samples t-tests, when comparing the average for the grammatical aspects of the second essay between experimental and control groups.

In the second essay, we find the differences between gender (in favor of female students) in the following variables: number of words $(p=0)$, percentage of adverbs $(p=0.001)$, number of sentences $(p=0)$, total emotions $(p=0)$, different emotions $(p=0)$, percentage of conjuncts $(p=0.026)$, with the statistical degree of confidence of $95 \%$, which was obtained after applying the independent-samples $\mathrm{t}$-tests, when comparing the average for the grammatical aspects of the second essay between females and males.

In the variables of originality and usage of fantastic elements, gender was not relevant, while for the grammatical variables, gender seems to be important for written expression in a foreign language. Additionally, for the variables related to emotions, we find statistically significant variables that shows female students tend to demonstrate more emotions when writing in a foreign language, even when the topic is neutral ("The place where I live").

\subsubsection{Progress Variable}

To analyze the improvement of the written expression by gender and experimental/control group, we created the values of progress by subtracting the value of each variable of the first essay from the variables of the second essay. In Table 4, we can find the results following both indicators.

Table 4. Average values of progress variables in each group.

\begin{tabular}{|c|c|c|c|c|c|c|c|c|c|c|c|c|}
\hline \multirow{2}{*}{$\begin{array}{l}\text { Group } \\
\text { Gender }\end{array}$} & \multicolumn{2}{|c|}{$\begin{array}{l}\text { Number of } \\
\text { Words }\end{array}$} & \multicolumn{2}{|c|}{$\begin{array}{l}\text { Percentage of } \\
\text { Verbs }\end{array}$} & \multicolumn{2}{|c|}{$\begin{array}{c}\text { Percentage of } \\
\text { Adjectives }\end{array}$} & \multicolumn{2}{|c|}{$\begin{array}{l}\text { Percentage of } \\
\text { Adverbs }\end{array}$} & \multicolumn{2}{|c|}{$\begin{array}{c}\text { Morphosyntactic } \\
\text { Errors }\end{array}$} & \multicolumn{2}{|c|}{ Lexical Errors } \\
\hline & M & $\mathrm{F}$ & M & $\mathrm{F}$ & $\mathrm{M}$ & $\mathrm{F}$ & $\mathrm{M}$ & $\mathrm{F}$ & M & $\mathrm{F}$ & M & $\mathrm{F}$ \\
\hline Experimental & -0.52 & 17.36 & 1.80 & 2.35 & 0.24 & 0.80 & 0.09 & 0.09 & -0.43 & 0.96 & 0.11 & 0.44 \\
\hline \multirow[t]{2}{*}{ Control } & 26.18 & 24.24 & 9.89 & 1.35 & 0.38 & 0.71 & -0.05 & 1.52 & 1.56 & 0.21 & 1.23 & 1.07 \\
\hline & \multicolumn{2}{|c|}{$\begin{array}{l}\text { Semantic } \\
\text { Errors }\end{array}$} & \multicolumn{2}{|c|}{$\begin{array}{l}\text { Argument } \\
\text { Leaps }\end{array}$} & \multicolumn{2}{|c|}{ Emotions } & \multicolumn{2}{|c|}{$\begin{array}{l}\text { Emotions } \\
\text { (Total) }\end{array}$} & \multicolumn{2}{|c|}{$\begin{array}{l}\text { Percentage of } \\
\text { Conjuncts }\end{array}$} & \multicolumn{2}{|c|}{$\begin{array}{c}\text { Percentage of } \\
\text { Hedges }\end{array}$} \\
\hline Gender & $\mathrm{M}$ & $\mathrm{F}$ & $\mathrm{M}$ & $\mathrm{F}$ & $\mathrm{M}$ & $\mathrm{F}$ & $\mathrm{M}$ & $\mathrm{F}$ & M & $\mathrm{F}$ & $\mathrm{M}$ & $\mathrm{F}$ \\
\hline Experimental & 0.09 & 0.30 & -0.28 & 0.13 & 0.52 & 1.04 & 0.75 & 1.60 & 0.16 & 0.21 & 0 & 0.01 \\
\hline \multirow[t]{2}{*}{ Control } & 0.81 & 0.38 & -0.15 & -0.07 & 0.5 & 0.65 & 1.07 & 1.48 & -0.17 & 0.20 & 0 & -0.09 \\
\hline & \multicolumn{2}{|c|}{$\begin{array}{l}\text { Percentage of } \\
\text { Amplifiers }\end{array}$} & \multicolumn{2}{|c|}{$\begin{array}{c}\text { Percentage of } \\
\text { Demonstratives }\end{array}$} & \multicolumn{2}{|c|}{$\begin{array}{l}\text { Percentage of } \\
\text { Subordinated } \\
\text { Sentences }\end{array}$} & \multicolumn{2}{|c|}{$\begin{array}{l}\text { Number of } \\
\text { Sentences }\end{array}$} & \multicolumn{4}{|c|}{ Total Progress } \\
\hline Gender & M & $\mathrm{F}$ & M & $\mathrm{F}$ & M & $\mathrm{F}$ & M & $\mathrm{F}$ & & & & \\
\hline Experimental & 0.16 & 0 & 0.38 & 0.42 & 0.21 & 0.03 & -0.12 & 0.76 & & & & \\
\hline Control & 0 & 0.32 & 0.19 & 0.17 & 0.07 & 0.75 & 1.63 & 1.06 & & & & \\
\hline
\end{tabular}

The column total progress shows the global result of progress for each group. This was calculated based on adding all the variables and subtracting the "error variables" (i.e., morphosyntactic, lexical and semantic errors, as well as argument leaps between phrases). The percentage values were transformed into the proportions.

We can detect that female students have higher progress than male students, independently of belonging to the experimental or control group. 
When analyzing the gender differences in the experimental and control groups, we applied the independent-samples t-test to compare the average values of the variables of the pre-test with the corresponding variables of post-test (i.e., gender as a factor variable). The results show significant differences between male and female students $(p=0.007)$. Female students improved in almost all indicators in the experimental groups. When applying the same analysis to the control groups, the gender differences disappear $(p>0.05)$.

\subsubsection{Narrative Creativity and Written Expression}

In Table 5, the average values of the variable of total progress for the high and low quartiles of narrative creativity can be observed (i.e., without considering the experimental/control condition and considering it).

Table 5. Total progress in written expression in comparison with NC for both the control and experimental groups, together and separately.

\begin{tabular}{ccccccc}
\hline \multirow{2}{*}{ Characteristics } & \multicolumn{2}{c}{ NC-All } & \multicolumn{2}{c}{ NC-Experimental } & \multicolumn{2}{c}{ NC-Control } \\
\cline { 2 - 7 } & Low & High & Low & High & Low & High \\
\hline N & 33 & 29 & 24 & 23 & 9 & 6 \\
Average & 12.2989 & 26.2245 & 9.9649 & 22.4192 & 18.5229 & 40.6961 \\
SD & 36.06236 & 47.09660 & 39.90325 & 46.81687 & 40.6961 & 49.60262 \\
\hline
\end{tabular}

We can observe that, without considering the experimental/control condition the medium and low creativity groups have similar indicators. Nevertheless, the high creativity group is considerably different. When applying the independent-samples t-test to analyze low NC and high NC, the results are statistically insignificant $(p>0.05)$. One-way analysis of variance (ANOVA) does not show significant results either.

When comparing the progress between low NC and high NC in experimental groups, the results are not statistically significant.

When comparing the progress between low NC and high NC in control groups, the results are statistically significant $(p=0.01)$.

An interrelation between the narrative creativity and the capacity to improve the written expression in foreign language can be observed, although the quasi-experimental design of the present study does not allow analysis of all the dimensions of this relationship.

\section{Discussion}

It was detected that the students with higher narrative creativity tend to show a higher capacity for improvement in written expression in a foreign language. Despite these results not being statistically significant, they demonstrate the presence of the interrelation between these two factors. We can suppose that the size of the sample, number and distribution of participants into experimental and control groups obstructs the equivalency of the groups. This tendency goes along with findings by Albert and Kormos [49], or Albert [50], who, in different studies, obtain varying results regarding creativity and language learning.

As for Albert [50] and McDonough, Crawford and Mackey [51], we can observe that creativity does not tend to be related to all language levels. For example, as the previous authors suggest in their study, there may be no impact of creativity on phonetic levels, as they have a mechanical character and, consequently, are not related to creativity. McDonough, Crawford and Mackey [51] also conclude there is no impact purely on the linguistic level (which also does not imply creativity, i.e., when speaking about learning a grammar rule, it is hard to involve creative processes, as it is about memorizing a rule or similar process). In our study, we have also detected that creativity is not necessarily related with 
the grammatical dominion of the language: both control and experimental groups made a progress in linguistic variables.

We have noted the statistically significant progress in grammar variables for female participants, but this is not related to creativity and probably the progress in grammar is due to other factors (i.e., official instruction in English classes). The aim of the project was to improve creativity and fantasy, and we have statistically demonstrated this change. However, the creative writing project we held in schools did not focus on grammar, as the aim was to foster narrative creativity and make students feel confident in their written expression, trying to avoid mental blocks when thinking of the mechanical part of writing (i.e., grammar).

The results of improvement in originality and usage of fantastic elements show the improvement in the variables that are most connected with creativity and, specifically, form part of creativity itself (this falls in line with Ottó [48], who finds the positive impact on originality and fluency). Taking into account that, generally, all the participants improved in total progress for grammar variables, this signifies that the formal English grammar instruction students received in other lessons produced results parallel with the skills our creative workshop could develop. This also signifies that two different areas of written expression were developed for the students of experimental groups: at the same time as improving their grammar skills in the common lessons (the same is applied to the control groups), they also improved collateral parts of creative thinking related to flexibility, fluency and originality (creativity indicators introduced by Guilford), which are not usually instructed at school (this part cannot be seen in most participants of the control groups, they improved only in grammar aspects).

As Pishghadam and Javdan-Mehr [34] or Ghonsooly [39] detect, language proficiency has an impact on creativity, and in future studies, it may be necessary to create this category as a separate variable, to achieve corresponding results at the level where the relationship with creativity and language proficiency is clear. Nevertheless, our limitations consist of the fact that the groups at schools where the project was held were created without following any additional criteria, as both schools offered to work with existing groups at the third stage of secondary education. The situation with school organization did not enable creating groups based on other criteria (such as, for example, creativity level or language proficiency), as this enters in conflict with the official schedule of the students and curricula indications. The fact that the project was held in official instruction time reduced the possibility of participants to leave the project, although even in our case there was a loss of $21.5 \%$ of participants, due to irregular school attendance. The mortality of the sample is the standard problem of longitudinal studies held in the field of creativity [69]. Therefore, analyzing the academic impact of creativity and academic results highlight the difficulties in carrying out longitudinal studies to analyze creative processes, due to the time limitations and the high percentage that leave the project, with which we have had a similar problem. Additionally, research of the studies carried out in the field of creativity and foreign language learning, like Albert [50], Ghonsooly [39] or Sadykova and Shelestova [52], worked with limited number of participants (41, 120 and 58, respectively). Only the sample in or Liao, Chen, Chen and Chang [53] is more substantial $(\mathrm{N}=256)$.

To sum up, two important aspects need to be considered in future studies. First of all, there is a need to verify the statistical significance of the impact of narrative creativity on academic results, amplifying the sample of participants. Secondly, the groups need to be created following the language proficiency level, as several studies find differences precisely in higher levels of foreign language. In the higher levels of language proficiency, students start to be more exposed to another language culture, and this begins to impact them on a cognitive level. The difficulty of both needs is significant, but the studies show that these are the obstacles that obstruct obtaining clearer results.

Finally, in the data analysis process, we detected that female students of the experimental groups showed major improvement in the second essay (i.e., improving the usage of lexical, semantic and grammatical elements, and at the same time, reducing the number of errors). In the control groups we do not find gender differences when comparing both essays. This points out that a gender difference exists in the capacity to improve written expression in a foreign language. Baer and Kaufman [70] 
conduct a thorough analysis of all the studies in the field of creativity to detect the gender differences concerning creativity, and explain the possible differences from environmental and biological points of view. They conclude that, usually, the studies show no differences between males and females regarding areas of creativity, but when there are some, they usually are in favor of girls. In Abraham [71], a wide review of psychological and neuroscientific studies around gender differences in creativity was carried out, but the author also underlines the controversy around the results in this field and, at the same time, the need for further research, as the answer to the question about gender differences in creativity would not be a simple yes or no, but one of complex structures.

Nevertheless, as far as our findings detect, no studies have been conducted that research creativity and foreign language learning while focusing on gender differences. As our results are statistically justified, it seems to be a new topic to research and discuss, taking into account the gender differences in the analysis of the foreign language learning process.

\section{Conclusions}

We have demonstrated that the students of the experimental groups who participated in the project based on creative activities showed statistically significant improvement for the dimensions of originality and usage of fantastic elements. We can conclude that fostering the usage of creativity in the classroom helps students to improve, primarily, these aspects of their writing. This improvement is important as it is associated with a number of personal values that are not usually considered in education, such as fluency, imagination, fantasy and other cognitive benefits.

Additionally, we detected that female students of the experimental groups showed major improvement in the second essay (i.e., improving the usage of lexical, semantic, and grammatical elements, while simultaneously reducing the number of errors). In the control groups, we do not find gender differences when comparing both essays. This points out that a gender difference exists in the capacity to improve written expression in foreign language. It would be worthwhile to analyze the possible reasons for these results in future studies.

Finally, the results of the present study indicate that the students with higher narrative creativity demonstrate more improvement in written expression. Although these results do not have statistical significance, future studies need to be carried out to verify this tendency.

Author Contributions: Conceptualization, T.P.; J.L.O.-M. and F.Z.-O.; methodology, T.P.; J.L.O.-M.; F.Z.-O. and G.G.-V.; software, F.Z.-O. and G.G.-V.; formal analysis, T.P.; J.L.O.-M.; F.Z.-O. and G.G.-V.; investigation, T.P. and J.L.O.-M.; resources, T.P.; J.L.O.-M.; F.Z.-O. and G.G.-V.; data curation, F.Z.-O. and G.G.-V.; writing-original draft preparation, T.P. and J.L.O.-M.; writing-review and editing, T.P.; J.L.O.-M.; F.Z.-O. and G.G.-V.; visualization, T.P.; J.L.O.-M.; F.Z.-O. and G.G.-V.; supervision, J.L.O.-M. and F.Z.-O. All authors have read and agreed to the published version of the manuscript.

Funding: This research received no external funding.

Conflicts of Interest: The authors declare no conflict of interest.

\section{References}

1. García-Ramírez, J.M.; Hazir, M. Creativity and Cognitive Closure. ReiDoCrea 2015, 4, 18-23.

2. García-Ramírez, J.M. Predictibilidad and Creatividad Narrativa. Ulu 2016, 1, 1-6.

3. McCracken, J.L. Examining the Impact of Formal and Informal Learning on the Creativity of Women Inventors. In Proceedings of the 39th Annual Adult Education Research Conference Proceedings, San Antonio, TX, USA, 15-16 May 1998.

4. Artola, T.; Barraca, J.; Mosteiro, P.; Ancillo, I.; Poveda, B.; Sánchez, N. PIC-A Prueba de Imaginación Creativa para Adultos; TEA-Ediciones: Madrid, Spain, 2012.

5. McCabe, M.P. Influence of creativity and intelligence on academic performance. J. Creat. Behav. 1991, 25, 116-122. [CrossRef]

6. Kurtzman, L.A. A study of school attitudes, peer acceptance, and personality of creative adolescents. Except. Childr. 1967, 34, 157-162. [CrossRef] 
7. Silvia, P.J. Creativity and intelligence revisited: A latent variable analysis of Wallach and Kogan (1965). Creat. Res. J. 2008, 20, 34-39. [CrossRef]

8. Puertas-Molero, P.; González-Valero, G.; Sánchez-Zafra, M. Influencia de la práctica físico deportiva sobre la Inteligencia Emocional de los estudiantes: Una revisión sistemática. ESHPA 2017, 1, 10-24.

9. Getzels, J.W.; Jackson, P.W. Creativity and Intelligence; Wiley \& Sons: New York, NY, USA, 1962.

10. Torrance, E.P. Guiding Creative Talent; Prentice Hall: Englewood Cliffs, NJ, USA, 1962.

11. Torrance, E.P. Torrance Tests of Creative Thinking; Ginn \& Company: Lexington, KE, USA, 1974.

12. Michalko, M. Thinking like a genius: Eight strategies used by the supercreative, from Aristotle and Leonardo to Einstein and Edison. Future 1998, 32, 21.

13. Srinivasan, N. Cognitive neuroscience of creativity: EEG based approaches. Methods 2007, 42, 109-116. [CrossRef]

14. Smith, J.K.; Smith, L.F. Educational Creativity. In Handbook of Creativity; Sternberg, R.J., Kaufman, J.C., Eds.; Cambridge University Press: Cambridge, UK, 2010; pp. 250-264.

15. Amabile, T.M. The personality of creativity. Creat. Living 1986, 15, 12-16.

16. Runco, M.A. Children's divergent thinking and creative ideations. Dev. Rev. 1992, 12, 233-264. [CrossRef]

17. Renzulli, J.S. A general theory for the development of creative productivity through the pursuit of ideal acts of learning. Gift. Child Q. 1992, 36, 170-182. [CrossRef]

18. Sternberg, R.J. Creative thinking in the classroom. Scand. J. Educ. Res. 2003, 47, 325-338. [CrossRef]

19. Craft, A. An Analysis of Research and Literature on Creativity in Education. Available online: http://www. creativetallis.com/uploads/2/2/8/7/2287089/creativity_in_education_report.pdf (accessed on 1 May 2020).

20. Beghetto, R.A. Creativity in the Classroom. In Handbook of Creativity; Sternberg, R.J., Kaufman, J.C., Eds.; Cambridge University Press: Cambridge, UK, 2010; pp. 447-466.

21. Guilford, J.P. Creativity. Am. Psychol. 1950, 5, 444-454. [CrossRef] [PubMed]

22. Vygotsky, L.S. Imagination and creativity in childhood. J. Russ. East Eur. Psychol. 2004, 42, 7-97. [CrossRef]

23. Cuevas-Romero, S. Creativity in education, its development from a pedagogical perspective. J. Sport Health Res. 2013, 5, 221-228.

24. Hennessey, B.A.; Amabile, T.M. Creativity and Learning; NEA Professional Library: Washington, DC, USA, 1987.

25. Piasecka, L. Tinker, Tailor ... : Creativity in Foreign Language Learning and Teaching. In Challenges of Second and Foreign Language Education in a Globalized World; Pawlak, M., Mystkowska-Wiertelak, A., Eds.; Springer: Cham, Switzerland, 2017; pp. 89-106. [CrossRef]

26. Constantinides, M. Creating creative teachers. In Creativity in the English Language Classroom; Maley, A., Peachey, N., Eds.; Britis Council: London, UK, 2015; pp. 115-122.

27. Sawyer, R.K.; John-Steiner, V.; Moran, S.; Sternberg, R.; Feldman, D.H.; Csikszentmihalyi, M. Creativity and Development; Oxford University Press: New York, NY, USA, 2003.

28. Plucker, J.; Beghetto, T.A.; Dow, G. Why isn't creativity more important to educational psychologists? Potential, pitfalls and future directions in creativity research. Educ. Psychol. 2004, 39, 83-96. [CrossRef]

29. Freund, P.A.; Holling, H. Creativity in the classroom: A multilevel analysis investigating the impact of creativity and reasoning on GPA. Creat. Res. J. 2008, 20, 309-318. [CrossRef]

30. Beghetto, R.A.; Kaufman, J.C. Toward a broader conception of creativity: A case for "mini-c" creativity. Psychol. Aesthet. Creat. Arts 2007, 1, 73-79. [CrossRef]

31. Hennessey, B. The Creativity-Motivation Connection. In Handbook of Creativity; Sternberg, R.J., Kaufman, J.C., Eds.; Cambridge University Press: Cambridge, UK, 2010; pp. 342-365.

32. Common European Framework of Reference for Languages. 2002. Available online: https://rm.coe.int/ 16802fc1bf (accessed on 20 March 2020).

33. Common European Framework of Reference for Languages: Learning, Teaching, Assessment. Companion Volume with New Descriptors. 2018. Available online: https://rm.coe.int/cefr-companion-volume-with-newdescriptors-2018/1680787989 (accessed on 20 March 2020).

34. Pishghadam, R.; Javdan-Mehr, F. Learner Creativity and Performance in Written Narrative Tasks. World J. Educ. 2011, 1, 115-125. [CrossRef]

35. Sternberg, R.J. The theory of successful intelligence and its implications for language aptitude testing. In Individual Differences and Instructed Language Learning; Robinson, P., Ed.; John Benjamins: Amsterdam, The Netherlands, 2002. 
36. Chomsky, N. Syntactic Structures; Mouton de Gruyter: Berlin, Germany, 2002.

37. Chomsky, N. Language and Mind; Cambridge University Press: Cambridge, UK, 2006.

38. Artola González, T.; Barraca Mairal, J.; Martín Azañedo, C.; Mosteriro Pintor, P.; Ancillo Gómez, I.; Poveda Ga-Noblejas, B. PIC-J Prueba de Imaginación Creativa Para Jóvenes; TEA-Ediciones: Madrid, Spain, 2008.

39. Ghonsooly, B. The effects of foreign language learning on creativity. Eng. Lang. Teach. 2012, 5, $161-167$. [CrossRef]

40. Ricciardelli, L.A. Creativity and bilingualism. J. Creat. Behav. 1992, 26, 242-254. [CrossRef]

41. Landry, R.J. A comparison of second language learners and monoloniguals on divergent thinking tasks at the elementary school level. Mod. Lang. J. 1974, 58, 10-15. [CrossRef]

42. Cummins, J. The influence of bilingualism on cognitive growth: A synthesis of research findings and explanatory hypothesis. Work. Pap. Biling. 1976, 9, 1-43.

43. Van Dijk, M.; Kroesbergen, E.H.; Blom, E. Bilingualism and Creativity: Towards a Situated Cognition Approach. J. Creat. Behav. 2019, 53, 178-188. [CrossRef]

44. Lambert, W.E.; Tucker, G.R. Bilingual Education of Children: The St. Lambert Experiment; Newbury House Publishers: Rowley, MA, USA, 1972.

45. Hommel, B.; Colzato, L.S.; Fischer, R.; Christoffels, I.K. Bilingualism and creativity: Benefits in convergent thinking come with losses in divergent thinking. Front. Psychol. 2011, 2, 1-5. [CrossRef] [PubMed]

46. Kharkhurin, A.V. The effect of linguistic proficiency, age of second language acquisition, and length of exposure to a new cultural environment on bilinguals' divergent thinking. Biling. Lang. Cogn. 2008, 11, 225-243. [CrossRef]

47. Kharkhurin, A.V. Sociocultural differences in the relationship between bilingualism and creative potential. J. Cross-Cult. Psychol. 2010, 41, 776-783. [CrossRef]

48. Ottó, I. The relationship between individual differences in learner creativity and language learning success. TESOL Q. 1998, 32, 763-773. [CrossRef]

49. Albert, A.; Kormos, J. Creativity and narrative task performance: An exploratory study. Lang. Learn. 2004, 54, 277-310. [CrossRef]

50. Albert, A. Learner creativity as a potentially important variable: Examining the relationships between learner creativity, language aptitude and level of proficiency. In Empirical Studies in English Applied Linguistics; Nikolov, M., Horváth, J., Eds.; Lingua Franca Csoport: Pécs, Hungary, 2006; pp. 77-98.

51. McDonough, K.; Crawford, W.H.; Mackey, A. Creativity and EFL Students' Language Use During a Group Problem-Solving Task. TESOL Q. 2015, 49, 188-199. [CrossRef]

52. Sadykova, A.G.; Shelestova, O.V. Creativity Development: The Role of Foreign Language Learning. Intern. J. Environ. Sci. Educ. 2016, 11, 8163-8181.

53. Liao, Y.H.; Chen, Y.L.; Chen, H.C.; Chang, Y.L. Infusing creative pedagogy into an English as a foreign language classroom: Learning performance, creativity, and motivation. Think. Ski. Creat. 2018, 29, $213-223$. [CrossRef]

54. Celaya, M.L.; Navés, T. Age-related Differences and associated Factors in Foreign Language Writing. Implications for L2 Writing Theory and School Curricula. In Writing in Foreign Language Contexts. Learning, Teaching, and Research; Manchón, R., Ed.; SLA: Toronto, ON, Canada, 2009; pp. 130-155.

55. Haan, P.; Van Esch, K. Assessing the development of foreign language writing skills: Syntactic and lexical features. In Corpus Linguistics beyond the Word: Corpus Research from Phrase to Discourse; Fitzpatrick, E., Ed.; Rodopi: Amsterdam, The Netherlands, 2007; pp. 185-202.

56. Hinkel, E. Second Language Writers' Text. In Linguistic and Rhetorical Features; LEA: Montclair, NJ, USA, 2002.

57. Pennebaker, J.W.; Seagal, J.D. Forming a Story: The Health Benefits of Narrative. J. Clin. Psychol. 1999, 55, 1243-1254. [CrossRef]

58. Graybeal, A.; Sexton, J.D.; Pennebaker, J.W. The Role of Story-Making in Disclosure Writing: The Psychometrics of Narrative. Psychol. Health 2002, 17, 571-581. [CrossRef]

59. Tajfel, H. Value and the perceptual judgement of magnitude. Psychol. Rev. 1957, 64, 192-204. [CrossRef] [PubMed]

60. Tajfel, H. Human Groups and Social Categories; Cambridge University Press: Cambridge, UK, 1981.

61. Llach, M.D.P.A. Lexical Errors and Accuracy in Foreign Language Writing; SLA: Toronto, ON, Canada, 2011.

62. Rodari, G. Gramática de la fantasía. In Introducción al Arte de Inventar Historias; Argos Vergara: Madrid, Spain, 1983. 
63. Kohan, S. Taller de Escritura Creativa; Salvat Editores: Barcelona, Spain, 1996.

64. Páez, E. Escribir. Manual de Técnicas Narrativas; Ediciones SM: Madrid, Spain, 2001.

65. Frank, C.; Rinvolucri, M. Creative writing. In Activities to Help Students Produce Meaningful Texts; Helbling Languages: Rum, Tirol, Austria, 2007.

66. Coronado, M. Escribir, Crear, Contar; Instituto Cervantes: Barcelona, Spain, 2014.

67. Rienda Polo, J. Claves de la composición escrita. In Didáctica de la Lengua and la Literatura; Mata Anaya, J., Núñez Delgado, M.P., Rienda Polo, J., Eds.; Ediciones Pirámide: Madrid, Spain, 2015; pp. 73-96.

68. Hlenschi-Stroie, V. Drama and creative writing: A blended tool. In Creativity in the English Language Classroom; Maley, A., Peachey, N., Eds.; British Council: London, UK, 2015; pp. 158-164.

69. Parnes, S.J.; Noller, R.B. Applied creativity: The creative studies project. Part II-Results of the two-year program. J. Creat. Behav. 1972, 6, 164-186. [CrossRef]

70. Baer, J.; Kaufman, J.C. Gender Differences in Creativity. J. Creat. Behav. 2011, 42, 75-105. [CrossRef]

71. Abraham, A. Gender and creativity: An overview of psychological and neuroscientific literature. Brain Imag. Behav. 2016, 10, 609-618. [CrossRef]

(C) 2020 by the authors. Licensee MDPI, Basel, Switzerland. This article is an open access article distributed under the terms and conditions of the Creative Commons Attribution (CC BY) license (http://creativecommons.org/licenses/by/4.0/). 